\title{
Changes of summer cloud water content in China from
}

\section{ERA-Interim reanalysis}

Qinglong You ${ }^{1,2 *}$, Juju Liu ${ }^{2}$, Nick Pepin ${ }^{3}$

1. Department of Atmospheric and Oceanic Sciences \& Institute of Atmospheric Sciences, Fudan University, 200438, Shanghai, China;

2. Key Laboratory of Meteorological Disaster, Ministry of Education (KLME), Nanjing University of Information Science and Technology (NUIST), Nanjing, 210044, China;

3. Department of Geography, University of Portsmouth, U.K.

* Corresponding author E-mail address: yqing1@126.com 13 14 15 16 17 18 9 20 21 


\section{Abstract:}

Cloud plays an important role in regulating radiation and energy exchange, and the hydrological cycle. In this study, the variability of summer vertical integral cloud water content (VCWC) (sum of cloud liquid water content and cloud ice water content) from ERA-Interim reanalysis is investigated over China from 1979-2016. We divide the country into regions dominated by monsoonal and non-monsoonal influences, and the Tibetan Plateau. Relationships between summer VCWC and surface mean temperature, precipitation and precipitable water (PW) are investigated by singular value decomposition. Summer VCWC decreases from southeast to northwest with the largest values in the southwestern China. Summer VCWC has increased in the non-monsoon and Tibetan Plateau sub-regions with rates of 1.04 and $3.39 \mathrm{~g} / \mathrm{m}^{2} /$ decade respectively, which corresponds to an increase of $\mathrm{PW}$, precipitation and surface mean temperature. Summer VCWC has decreased by $-2.71 \mathrm{~g} / \mathrm{m}^{2} /$ decade in the monsoon sub-region, related to decreased precipitation and PW as well as increased surface mean temperature. Temperature rises (decreases) will strengthen (weaken) the atmospheric circulation in favor of increased (decreased) summer VCWC in the nonmonsoon/Tibetan Plateau sub-region, but weaken (strengthen) the climate systems in the monsoon sub-region. This explains the contrasting correlations between temperature and summer VCWC in the different regions, suggesting summer VCWC in China is moderated by atmospheric circulation through combined influences of surface mean temperature and PW.

Key words: China; cloud water content; trend; 


\section{Introduction}

Cloud properties which include cloud water content (CWC) (sum of cloud liquid water content (CLWC) and cloud ice water content (CIWC)), cloud water path, cloud effective radius, cloud height and cloud thickness, play an important role in regulating both the energy and water budgets at the Earth's surface. In doing so, they also regulate the response of the atmospheric circulation to climate change [Gultepe and Isaac, 1997; Ntwali et al., 2017; Yang and Wang, 2012]. In climate models, clouds provide a link between the hydrological and atmospheric systems and thus have an important impact on the climate system, and are probably the largest uncertainty in understanding of climate change [Bony et al., 2015; IPCC, 2013; Norris et al., 2016]. The Intergovernmental Panel on Climate Change (IPCC) Fifth Assessment Report (AR5) reveals that the mean global surface air temperature has warmed by 0.85 [0.65 to $1.06]^{\circ} \mathrm{C}$ over the period 1880 to 2012 [IPCC, 2013]. Such warming should moderate the physical processes and attendant characteristics of clouds.

Temperature increases in China since the 1950s are shown to be more rapid than the global mean [Bannister et al., 2017; Ding et al., 2007; HJ Wang et al., 2012]. However, it is unclear how this temperature increase has influenced cloud properties over the same period. The occurrence and development of clouds and resultant precipitation are complex and remain sufficient obstacles to successful weather and climate prediction. This is because there are numerous cloud-radiation feedback processes which have to be combined in a climate model [Gultepe and Isaac, 1997; Ntwali et al., 2017; Yang 
and Wang, 2012]. CWC is critical for numerical weather prediction and climate projections [Yang and Wang, 2012], and some studies have analyzed characteristics of CWC in China using data from the ISCCP (International Satellite Cloud Climatology Project), Cloudsat satellite and ERA-Interim datasets [ $J$ Li et al., 2017a; $C$ Wu and Chou, 2013; Zhai and Eskridge, 1997]. These studies have shown that there is a clear seasonal change in both the amount and spatial distribution of CWC in China, and summer CWC is strongly influenced by the Asian summer monsoon, the topography of Tibetan Plateau, and variation in exposure to the mid-latitude westerly flow [X Li et al., 2011; Yang and Wang, 2012; Zhou and Yu, 2005].

However, there is limited studies on changes in summer CWC in China. Furthermore, understanding the physical and dynamical structures of clouds and therefore successful incorporation of cloud feedbacks into model simulations, is strongly dependent on how accurate CWC can be modelled in the atmosphere. In this study, the patterns and causes of temporal and spatial variation in summer CWC in China are studied which will provide essential understanding for future model development over the region.

\section{Dataset and method}

The ERA-Interim reanalysis data released by European Centre for Medium-Range Weather Forecasts (ECMWF) [Dee et al., 2011] is selected in this study. ERA-Interim is the most comprehensive set of assimilation satellite observation data in reanalysis data. It is an updated data set of ERA-15 and ERA40. Its cloud water content data is the forecast variables based on observation data and forecast mode [Dee et al., 2011]. 
ERA-Interim is generated using the ECMWF Integrated Forecasting System (IFS) Cy31r2 model and four-dimensional variational data assimilation (4D-Var). The horizontal resolution is increased to T255 with 37 vertical levels from $1000 \mathrm{hPa}$ to 1 hPa (http://data.ecmwf.int/data) [Dee and Uppala, 2009; Dee et al., 2011]. The period January 1979 to December 2016 is selected and June-August is defined as summer.

The climatic elements including specific humidity (q), CWC, CLWC and CIWC are obtained from ERA-Interim reanalysis. In addition, observations of surface mean temperature (2m) and precipitation in China for 1979-2015 are available as a highquality daily gridded dataset with $0.5^{\circ} \times 0.5^{\circ}$ resolution interpolated from 2400 stations [J Wu and Gao, 2013; Xu et al., 2009]. This was obtained from National Meteorological Information Center, China Meteorological Administration (http://data.cma.cn.).

To calculate the available water in the whole atmospheric column, the precipitable water (PW), the vertical integral of CLWC (VCLWC) and CIWC (VCIWC) are calculated as the vertically integrated horizontal transport between $1000 \mathrm{hPa}$ and 300 $\mathrm{hPa}$ using atmospheric reanalysis data. The vertical integral of CWC (VCWC) is the sum of VCLWC and VCIWC.

Methods for objectively analyzing the relationship between time and space change of two fields are MEOF (Multivariable Empirical Orthogonal Function), PCA (SingleFiled-based PCA), CCA (Canonical Correlation Analysis), and SVD (singular value decomposition) [HB Wu and $W u, 2005]$. Among them, SVD is the easiest to implement and explain. The SVD method is one of the most widely-used multivariate statistical 
techniques used in atmospheric science to determine the correlation patterns of two independent fields [Lanzante, 1984; Wallace et al., 1992].

The SVD method yields two singular vectors which define two sets of spatial patterns relevant to two input fields, and the expansion coefficients are computed from the two singular vectors separately. The singular values provide a measure of the fraction of the squared correlation accounted for by the corresponding singular vector, in the same manner as the eigenvalues of a correlation matrix provide a measure of the percentage of variance explained by eigen modes [Lanzante, 1984; Shen and Lau, 1995; Wallace et al., 1992]. To compare the results with maps of correlation coefficients, the singular vector matrices are scaled to one, equivalent to the temporal correlation coefficient between the expansion coefficient of the corresponding mode and the field variable at that same grid point [Wallace et al., 1992].

To study the relationships between the two field structures, the SVD method is applied to the correlations between precipitation, temperature, $\mathrm{PW}$ and VCWC in China. To identify statistically significant patterns from random noise, a Monte Carlo technique has been applied to test the significance of the SVD results [Overland and Preisendorfer, 1982].

Three sub-regions in China are defined by topography and geographical location (Figure 1) including 1) non-monsoon sub-region, 2) Tibetan Plateau sub-region and 3) monsoon sub-region, respectively. The demarcation line between the monsoon and non-monsoon climate zones (Daxinganling - Yinshan Mountains - Helan Mountain - 
Wushaoling - Bayan Hara - Tanggula - Gangdisi) and the geographical boundary of the Tibetan Plateau define the sub-regions [Ding et al., 2007; Liu et al., 2004; H J Wang et al., 2012; S W Wang and Gong, 2000; Y Q Wang and Zhou, 2005] .

\section{Results}

\subsection{Climatological distribution}

Figure 2 shows the climatological distribution of VCLWC, VCIWC, VCWC, PW, surface mean temperature and precipitation in China in summer (JJA) during 19792016. VCLWC decreases from the south and south-east to the north-west (Figure 2a), and VCIWC tends to be higher in southern regions, peaking in the western Sichuan basin (Figure 2b). The spatial distribution of VCWC is broadly similar to VCLWC, with largest values $\left(>0.25 \mathrm{~kg} / \mathrm{m}^{2}\right)$ in the south-west and smallest values $\left(<0.05 \mathrm{~kg} / \mathrm{m}^{2}\right)$ in the north-west (Figure 2c). PW is most concentrated in the southern and eastern parts of China, rather than Sichuan, and the maximum is slightly further east than VCLWC and VCIWC (Figure 2d). The distribution of surface mean temperature is strongly negatively correlated with elevation, as expected (Figure 2e). Precipitation decreases from south-east to north-west and has a broadly similar pattern to PW (Figure 2f).

Figure 3 shows pressure-latitude cross sections of CLWC, CIWC, and CWC for the three sub-regions. In the monsoon sub-region (top row), CLWC is concentrated around $22-36^{\circ} \mathrm{N}, 925 \sim 450 \mathrm{hPa},-10 \sim 25^{\circ} \mathrm{C}$ (Figure 3a), and the highest CIWC occurs between 27 and $40^{\circ} \mathrm{N}$ (Figure 3b). CWC on the other hand is concentrated south of $36^{\circ} \mathrm{N}$ and 
between $850 \sim 400 \mathrm{hPa}$ and $-15-20^{\circ} \mathrm{C}$. Values above $0.03 \mathrm{~g} / \mathrm{kg}$ are recorded at both 850 and $500 \mathrm{hPa}$ (Figure 3c). In the non-monsoon sub-region (second row), CLWC is much lower and mainly located at the domain of $800 \sim 400 \mathrm{hPa}, 15 \sim-10{ }^{\circ} \mathrm{C}$ (Figure 3d). CIWC is negligible over most of the domain (Figure 3e). CWC relates to topography, and surprisingly mountainous areas around $38^{\circ} \mathrm{N}$ in the south of the region show large values reaching over $0.02 \mathrm{~g} / \mathrm{kg}$ around $600-300 \mathrm{hPa},-40 \sim 5{ }^{\circ} \mathrm{C}$ (Figure $3 \mathrm{f}$ ). $\mathrm{CWC}$ therefore increases from north to south. In the Tibetan Plateau sub-region (bottom row), CLWC shows a distinct peak south of $31^{\circ} \mathrm{N}$ and below $450 \mathrm{hPa}$. Large values of $>0.04$ $\mathrm{g} / \mathrm{kg}$ create a plume of moist air which extends up from the surface to $500 \mathrm{hPa}$ and also extends slightly further north at around the $500 \mathrm{hPa}$ level (Figure 3g). The maximum CIWC on the other hand is further north around $34-36^{\circ} \mathrm{N}$ and at higher elevations (Figure 3h). CWC overall is dominated by CLWC so shows a similar distribution to the liquid component (Figure 3i).

In summary, VCWC is lowest in the non-monsoon sub-region (middle row) with slightly higher values in the mountainous areas of Xinjiang. VCWC in the Tibetan Plateau sub-region is extremely high particularly in the south. These patterns are broadly consistent with the distribution of precipitation and PW in these regions. VCWC in the monsoon sub-region shows a strong decreasing gradient from south to north but is nowhere near as high as in the southern parts of the Tibetan plateau subregion.

\subsection{Time series and trends}


169

170

171

172 the monsoon sub-region (top graphs on Figure 4), both VCLWC and VCIWC decrease

173

Figure 4 and Figure 5 represent time series and spatial trends of VCLWC, VCIWC, VCWC, PW, mean temperature and precipitation in the three regions in summer between 1979 and 2016. Table 1 summarizes the magnitude of some of these trends. In over most of the period, but there was a temporary increase in the 1990s. Both show similar inter-annual variability, with high correlation between them. Thus VCWC as a whole shows a similar decreasing trend. During the same period, PW on the other hand shows relatively little change, while temperature has increased and precipitation has shown no overall decrease. Therefore although precipitation shows broad similarities to VCWC and its components, it is not shown such a strong decrease as might be expected from the decline in VCLWC.

In the non-monsoon sub-region (middle graphs on Figure 4), VCLWC, VCIWC and VCWC show similar inter-annual variation, and overall there appears to be an increasing trend, although this is strongly influenced by the most recent years. PW has also increased, and the value for 2016 is exceptional. The rapid warming of surface mean temperature is clear, and the general increase in precipitation appears to be significantly correlated with VCLWC, VCIWC and VCWC.

In the Tibetan Plateau sub-region (bottom graphs on Figure 4), VCLWC, VCIWC and VCWC trends in general show an increase, but there has been a levelling off after the mid-1990s, similar to the non-monsoon sub-region. VCIWC has even decreased since 
189

190

191

192

193

194

195

196

197

198

199

200

201

202

203

204

205

206

207

the turn of the century. PW however shows a strong increasing trend, as does the surface air temperature.

Maps of spatial trends (Figure 5) show this in more detail. VCLWC, VCIWC and VCWC show broadly similar trend patterns, with the strongest positive trends over the whole period in western parts of China (west of $105^{\circ} \mathrm{E}$ ). The heart of northern and eastern China in the monsoon sub-region shows a decrease, particularly marked for VCIWC. PW shows most increase in western China and some coastal provinces whereas much of central China shows a negative trend. Surface mean temperature has shown pronounced warming everywhere, but especially at high elevations and latitudes. The most significant positive trends for precipitation occur in western China, which is similar to VCWC.

Table 1 lists trend values for the three sub-regions as a whole, and significant contrasts between regions are demonstrated. VCWC has increased most strongly in the Tibetan plateau region, along with PW. However trends in precipitation are insignificant. In summary, the three regions show some differences in trends, with the increases in VCWC being most systematic and widespread in the non-monsoon and Tibetan plateau sub-regions. VCWC shows significant inter-annual variation in the three sub-regions with the strongest long-term increase in parts of the non-monsoon and Tibetan Plateau sub-regions.

\subsection{SVD analysis}


Figure 6 shows the heterogeneous correlation between VCWC and PW (top row)/surface mean temperature (middle row)/precipitation (bottom row) and the time coefficient of the first mode of SVD for each respectively. Table 2 summarizes the correlation coefficients between VCWC, VCLWC, VCIWC, precipitation, PW and surface mean temperature in the three sub-regions during 1979-2016. In this way the various contributing factors towards variance in VCWC can be examined.

The first SVD mode for PW/VCWC represents $13 \%$ of the total variance, and the correlation coefficient between the expansion coefficients of the first SVD is 0.87 , which passes Monte-Carlo significance at $\mathrm{p}<0.05$ (Figure $6 \mathrm{a}, \mathrm{b}, \mathrm{c}$ ). For PW patterns, positive correlations occur for most of China, especially in the non-monsoon and Tibetan Plateau sub-regions. Some negative correlations are demonstrated in eastern China. This suggests that an increase (decrease) of PW in the non-monsoon and Tibetan Plateau sub-regions corresponds to a simultaneous increase (decrease) of VCWC in western China and decrease (increase) in eastern China.

The first SVD mode for surface mean temperature/VCWC represents $33.2 \%$ of the total variance, and the correlation coefficient between the expansion coefficients of the first SVD is $0.85(\mathrm{p}<0.05)$ (Figure $6 \mathrm{~d}, \mathrm{e}, \mathrm{f})$. Mean temperature shows positive correlations for the whole of China. VCWC shows positive correlations west of $105^{\circ} \mathrm{E}$ (except in the Xinjiang basin and central Yunnan basin), Jiangnan and South China, but negative correlations in most of eastern China. In most areas therefore an increase (decrease) of surface mean temperature in China corresponds to an increase (decrease) of VCWC in 
western China and the opposite in eastern China.

The first SVD mode for precipitation/VCWC represents $10.4 \%$ of the total variance, and the correlation coefficient between the expansion coefficients of the first SVD is $0.92(\mathrm{p}<0.05)$ (Figure $6 \mathrm{~g}, \mathrm{~h}, \mathrm{i})$. The precipitation shows positive correlations in northeast China and negative correlations in the northwest of the Tibetan Plateau and in southeast China. VCWC shows similar correlations patterns as precipitation. This suggests that the two variables are very strongly coupled. An increase (decrease) of precipitation in northeast China and decrease (increase) of precipitation in the northwest of Tibetan Plateau corresponds to an increase (decrease) of VCWC.

\subsection{Atmospheric circulation analysis}

To demonstrate how the atmospheric circulation interacts with VCWC in the monsoon (Figure 7), non-monsoon (Figure 8) and Tibetan Plateau (Figure 9) sub-regions respectively, atmospheric composite analyses of wind fields and wind speeds contrasting between strongly positive and negative VCWC years have been performed.

For the monsoon sub-region (box on Figure 7), low pressure in the Mongolian region at $700 \mathrm{hPa}$ intensifies water vapor convergence and encourages strong upward motion which is beneficial to the formation of VCWC over the monsoon sub-region (Figure 7a). Strong southwesterly airflow covers most of southern China to the east of the Tibetan Plateau and moisture is also pumped northwards around a high pressure ridge over Taiwan (Figure 7c). Both the Mongolian cyclone and the eastern Tibetan Plateau 
trough contribute to an increase of VCWC.

251

252

The atmospheric composite patterns of wind field and wind speed between the strongly positive and negative surface mean temperature years at both $700 \mathrm{hPa}$ and $500 \mathrm{hPa}$ are completely opposite to those for VCWC (Figure 7b,d). Warmth (cold) in the monsoon sub-region weakens (strengthens) the southwest summer monsoon, the eastern Plateau trough and the Mongolian cyclone, and therefore reduces (increases) the ascending motion of water vapor, resulting in reduced (increased) VCWC. This explains why the correlation between VCWC and surface mean temperature is strongly negative in the monsoon sub-region $(\mathrm{R}=-0.51$, Table 2$)$. More warming in the north of monsoon subregion decreases the latitudinal temperature gradient and therefore the pressure gradient and weakens the East Asian summer monsoon. This in turn limits water vapor transportation to the monsoon sub-region. The reduction of VCWC will increase the surface shortwave solar radiation flux and further increase the surface mean temperature, forming a negative feedback mechanism between VCWC and surface mean temperature in the monsoon sub-region.

In the non-monsoon sub-region (Figure 8), the composite analysis of wind field and wind speed at $700 \mathrm{hPa}$ and $500 \mathrm{hPa}$ indicates four possible water vapor channels contributing to VCWC. These are 1) southwesterly airflow around a cyclone over the Caspian Sea, 2) airflow originating from polar latitudes near Lake Baikal and arriving from the south-east after diverging from the Mongolian anti-cyclone, 3) southerly airflow to the east of a cyclone over the western Arabian Sea, and 4) southeasterly 
airflow originating from the Bay of Bengal arriving after traversing the Tibetan Plateau. The channels from the Mongolian anticyclone and the Bay of Bengal are strengthened by southeasterly airflow from South China Sea and the northwest Pacific Ocean. The dominant flow in the non-monsoon sub-region (box on Figure 8) appears to come from the high-latitude climate system, suggesting that meridional water vapor transport is critical to this region. It appears that the patterns for increased surface mean temperature are very similar to those for increased VCWC in this region, which implies that surface warming and increased VCWC are coupled together. Warming will increase both evaporation and saturation vapor pressure, which will cause an increase in PW. Moreover, the surface warming will tend to destabilize the atmosphere, and further promote VCWC increase. VCWC increase will help the formation of precipitation and prevent longwave radiation loss which could result in further warming.

In the Tibetan Plateau sub-region (Figure 9) at $500 \mathrm{hPa}$, the composite shows that three water vapor channels contribute to high VCWC: 1) southwesterly airflow to the east of a cyclone over Eastern Iran, 2) southwesterly airflow from Indian Ocean originating from the Bay of Bengal and ascending onto the plateau, and 3) southeasterly airflow from North-western Pacific and Southern China. It can be noted that these airflows mainly come from the western and southern inflow. A marked convergence zone between the southwesterly and southeasterly flows occurs near $32^{\circ} \mathrm{N}$ over the central Tibetan Plateau, which is conducive to ascending motion and an increase in VCWC. Composite patterns of the wind field at $500 \mathrm{hPa}$ between strongly positive and negative surface mean temperature show that surface warming will strengthen both water vapor 
channels and the wind shear over the plateau.

294

295

296

297

298

299

300

301

302

303

At $200 \mathrm{hPa}$, high pressure located over the Tibetan Plateau encourages upper level divergence, and therefore uplift and strong convective activity and high VCWC. The composite pattern of the wind field at $200 \mathrm{hPa}$ suggests that significant warming will strengthen this upper level (South Asia) high. More warming in the Tibetan Plateau subregion in comparison with regions to its south will increase the reversed meridional temperature gradient and strengthen the South Asian summer monsoon, resulting in more water vapor transport to the Tibetan Plateau sub-region. At the same time, warming in the lower troposphere will increase instability, strengthen upwards motion, enhance the upper-level South Asia high, promote convection, and further increase VCWC and precipitation. In turn, any VCWC increase will weaken longwave radiation loss which will result in temperature rise, especially at high elevations.

\section{Summary and Conclusions}

Based on reanalysis data sets (ERA-Interim) and station observations (precipitation and temperature), this study investigates patterns of summer CWC and its relationships with atmospheric circulation in three different regions of China during 1979-2016. Overall, both VCLWC and VCWC decrease from southeast to northwest, but the largest values are reported in the southwest. VCIWC has large values in the central regions of China with the largest value in western Sichuan. During the studied period, VCWC has 
increased in the non-monsoon and Tibetan Plateau sub-regions by 1.04 and 3.39 $\mathrm{g} / \mathrm{m}^{2} /$ decade respectively, which corresponds with simultaneous increases of PW, precipitation and surface mean temperature. In contrast, VCWC has decreased by -2.71 $\mathrm{g} / \mathrm{m}^{2} /$ decade in the monsoon sub-region, related to a decrease in precipitation and PW alongside the increase in surface mean temperature.

VCWC is moderated by the atmospheric circulation through combined influences of surface mean temperature and PW. Surface mean temperature rise (fall) will strengthen (weaken) the atmospheric circulation in favor of increased VCWC in the non-monsoon and Tibetan Plateau sub-regions, but weaken (strengthen) the climate systems in the monsoon sub-region. This explains the positive correlation between surface mean temperature and VCWC in the non-monsoon and Tibetan Plateau sub-regions but significantly negative correlation in the monsoon sub-region (Table 2). Meanwhile, PW increases will moderate the regional atmospheric circulation systems in favor of increased VCWC in all of the three sub-regions (Figure 10). On the other hand, surface mean temperature will also influence PW. For example, surface mean temperature increase in the non-monsoon sub-region is conducive to increased evaporation and warmer temperatures will increase the saturation vapor pressure, leading to increased PW.

Different rates of local temperature change can influence the temperature gradient between regions, which can in turn influence water vapor transport between these regions. For example, more rapid warming at the surface in the Tibetan Plateau sub- 
region than further south in the free atmosphere will enhance the plateau heat source effect (the meridional temperature gradient is already reversed in summer), strengthen the South Asian summer monsoon, and result in an increase of water vapor transport to the plateau region. In contrast, more warming in the north of the monsoon sub-region than in the south will decrease the meridional temperature gradient, pressure gradient, and weaken the East Asian summer monsoon, resulting in a decrease of water vapor transport across the monsoon sub-region. Thus warming appears to have contradictory influences on VCWC in the two parts of China. Clarifying the influences of atmospheric circulation on VCWC in China is thus an urgent task.

The sole use of ERA-Interim reanalysis is not enough to fully represent VCWC across China and comparisons from multiple reanalyses are necessary to provide more indepth analysis. There are known discrepancies between ERA-Interim and NCEP/NCAR in depicting precipitation and atmospheric moisture for example [ $\mathrm{J}$ Li et al., 2017a; P Li et al., 2017b; R Wang et al., 2017a; Z Wang et al., 2017b]. Even for satellite retrieval products, cloud properties still suffer from large uncertainties due to the senor ability, retrieval algorithm and sample timing [Klein et al., 2013]. As for reanalyzed or modelled cloud properties, the spatial pattern may be captured by the reanalysis but the temporal trend is still questionable [Jiang et al., 2012; Klein et al., 2013; Stubenrauch et al., 2013]. There are other datasets available for the cloud water used in this study, and there have changes among datasets varied with regions and seasons. The multiple satellite observations (MODIS, ISCCP, and CloudSat) and reanalysis data (ERA-Interim and CFSR) are compared for cloud water in a recent study 
[Geng, 2017]. In terms of cloud water content, ERA-Interim shows high consistency with MODIS and CFSR all showed high consistency. Although the distribution of the high and low values of the four datasets is relatively consistent, the correlation coefficient among them is above 0.6 , but there are still differences in the specific values of the cloud water path [Geng, 2017]. Though the reanalysis provides relative coherent physics between cloud and meteorological fields through its host assimilation model, the model parameterization biases are unavoidable. Thus, it should be cautious to use the reanalyzed cloud properties for climate trend analysis. Furthermore there are also strong seasonal differences in both the intensity and spatial distribution of VCWC, and so an examination beyond the summer is required. Additional work will focus on other seasons and the extent to which other reanalyses corroborate our current findings.

Acknowledgments. This study is supported by National Key R\&D Program of China (2016YFA0601702), National Natural Science Foundation of China (41771069). This study is also funded by "the Priority Academic Program Development of Jiangsu Higher Education Institutions" (PAPD).

\section{References}

Bannister, D., M. Herzog, H.-F. Graf, J. S. Hosking, and C. A. Short (2017), An Assessment of Recent and Future Temperature Change over the Sichuan Basin, China, Using CMIP5 Climate Models, Journal of Climate, 30(17), 6701-6722. 
378

379

Bony, S., et al. (2015), Clouds, circulation and climate sensitivity, Nature Geoscience, 8, 261, doi:10.1038/ngeo2398.

Dee, D. P., and S. Uppala (2009), Variational bias correction of satellite radiance data in the ERA-Interim reanalysis, Quarterly Journal of the Royal Meteorological Society, 135(644), 1830-1841, doi:10.1002/qj.493.

Dee, D. P., et al. (2011), The ERA-Interim reanalysis: configuration and performance of the data assimilation system, Quarterly Journal of the Royal Meteorological Society, 137(656), 553-597, doi:10.1002/qj.828.

Ding, Y. H., G. Y. Ren, Z. C. Zhao, Y. Xu, Y. Luo, Q. P. Li, and J. Zhang (2007), Detection, causes and projection of climate change over China: An overview of recent progress, Advances in Atmospheric Sciences, 24(6), 954-971.

Geng, R. (2017), Comparison and analysis of atmospheric water cycle variables based on satellite and reanalysis data, Hefei: University of Science and Technology of China (in Chinese), 1-52.

Gultepe, I., and G. A. Isaac (1997), Liquid Water Content and Temperature Relationship from Aircraft Observations and Its Applicability to GCMs, Journal of Climate, 10(3), $446-452$.

IPCC (2013), Summary for Policymakers of Climate change 2013: The Physical Science Basis. Contribution of Working Group I to the Fifth Assessment Report of the Intergovernmental Panel on Climate Change Cambridge, UK: Cambridge University Press.

Jiang, J. H., et al. (2012), Evaluation of cloud and water vapor simulations in CMIP5 
400

401

402

403

404

405

406

407

408

409

410

411

412

413

414

415

416

417

418

419

420

421

climate models using NASA “A-Train” satellite observations, Journal of Geophysical Research: Atmospheres, 117(D14), doi:10.1029/2011JD017237.

Klein, S. A., Y. Zhang, M. D. Zelinka, R. Pincus, J. Boyle, and P. J. Gleckler (2013), Are climate model simulations of clouds improving? An evaluation using the ISCCP simulator, Journal of Geophysical Research: Atmospheres, 118(3), 1329-1342, doi:doi:10.1002/jgrd.50141.

Lanzante, J. R. (1984), A Rotated Eigenanalysis of the Correlation between $700 \mathrm{mb}$ Heights and Sea Surface Temperatures in the Pacific and Atlantic, Monthly Weather Review, 112(11), 2270-2280.

Li, J., W.-C. Wang, X. Dong, and J. Mao (2017a), Cloud-radiation-precipitation associations over the Asian monsoon region: an observational analysis, Climate Dynamics, 49(9), 3237-3255, doi:10.1007/s00382-016-3509-5.

Li, P., T. Zhou, and X. Chen (2017b), Water vapor transport for spring persistent rains over southeastern China based on five reanalysis datasets, Climate Dynamics, in press. Li, X., Z. Wen, and W. Zhou (2011), Long-term Change in Summer Water Vapor Transport over South China in Recent Decades, Journal of the Meteorological Society of Japan, 89A, 271-282.

Liu, B. H., M. Xu, M. Henderson, Y. Qi, and Y. Q. Li (2004), Taking China's temperature: Daily range, warming trends, and regional variations, 1955-2000, Journal of Climate, 17(22), 4453-4462.

Norris, J. R., R. J. Allen, A. T. Evan, M. D. Zelinka, C. W. O’Dell, and S. A. Klein (2016), Evidence for climate change in the satellite cloud record, Nature, 536, 72, 
doi:10.1038/nature18273.

Ntwali, D., E. Mugisha, F. Vuguziga, and D. Kakpa (2017), Liquid and ice water content in clouds and their variability with temperature in Africa based on ERA-Interim, JRA55, MERRA and ISCCP, Meteorology and Atmospheric Physics, 129(1), 17-34, doi:10.1007/s00703-016-0447-z.

Overland, J. E., and R. W. Preisendorfer (1982), A Significance Test for Principal Components Applied to a Cyclone Climatology, Monthly Weather Review, 110(1), 1-4. Shen, S., and K. M. Lau (1995), Biennial Oscillation Associated with the East Asian Summer Monsoon and Tropical Sea Surface Temperatures, Journal of the Meteorological Society of Japan. Ser. II, 73(1), 105-124.

Stubenrauch, C. J., et al. (2013), Assessment of Global Cloud Datasets from Satellites: Project and Database Initiated by the GEWEX Radiation Panel, Bulletin of the American Meteorological Society, 94(7), 1031-1049, doi:10.1175/BAMS-D-1200117.1.

Wallace, J. M., C. Smith, and C. S. Bretherton (1992), Singular Value Decomposition of Wintertime Sea Surface Temperature and 500-mb Height Anomalies, Journal of Climate, 5(6), 561-576.

Wang, H. J., J. Q. Sun, H. P. Chen, Y. L. Zhu, Y. Zhang, D. B. Jiang, X. M. Lang, K. Fan, E. T. Yu, and S. Yang (2012), Extreme Climate in China: Facts, Simulation and Projection, Meteorologische Zeitschrift, 21(3), 279-304, doi:10.1127/0941$2948 / 2012 / 0330$.

Wang, R., Y. Fu, T. Xian, F. Chen, R. Yuan, R. Li, and G. Liu (2017a), Evaluation of 
444

445

446

447

448

449

450

451

452

453

454

455

456

457

458

459

460

461

$462 \quad 1111$.

463

464

465

Atmospheric Precipitable Water Characteristics and Trends in Mainland China from 1995 to 2012, Journal of Climate, 30(21), 8673-8688, doi:10.1175/JCLI-D-16-0433.1.

Wang, S. W., and D. Y. Gong (2000), Enhancement of the warming trend in China, Geophysical Research Letters, 27(16), 2581-2584.

Wang, Y. Q., and L. Zhou (2005), Observed trends in extreme precipitation events in China during 1961-2001 and the associated changes in large-scale circulation, Geophysical Research Letters, 32(9), L09707.

Wang, Z., A. Duan, S. Yang, and K. Ullah (2017b), Atmospheric moisture budget and its regulation on the variability of summer precipitation over the Tibetan Plateau, Journal of Geophysical Research: Atmospheres, 122(2), 614-630, doi:10.1002/2016JD025515.

Wu, C., and M. Chou (2013), Tibetan Plateau westerly forcing on the cloud amount over Sichuan Basin and the early Asian summer monsoon, Journal of Geophysical Research: Atmospheres, 118(14), 7558-7568, doi:10.1002/jgrd.50580.

Wu, H. B., and L. Wu (2005), Methods for diagnosing and forecasting climate variability, Beijing: China Meteorological Press (in Chinese), 113-143.

Wu, J., and X. J. Gao (2013), A gridded daily observation dataset over China region and comparison with the other datasets, Chinese Journal of Geophysics, 56(4), 1102Xu, Y., X. J. Gao, S. Y. Yan, C. H. Xu, Y. Shi, and F. Giorgi (2009), A daily temperature dataset over China and its application in validating a RCM simulation, Advances in Atmospheric Sciences, 26(4), 763-772. 

Contents over China during Summer, Chinese Journal of Atmospheric Sciences (in Chinese), 36(1), 89-101.

469 Zhai, P., and R. E. Eskridge (1997), Atmospheric Water Vapor over China, Journal of 470 Climate, 10(10), 2643-2652.

471 Zhou, T.-J., and R.-C. Yu (2005), Atmospheric water vapor transport associated with 472 typical anomalous summer rainfall patterns in China, Journal of Geophysical Research: 473 Atmospheres, 110(D8), D08104, doi:10.1029/2004JD005413.

474

475

476

477

478

479

480

481

482

483

484

485

486

487 


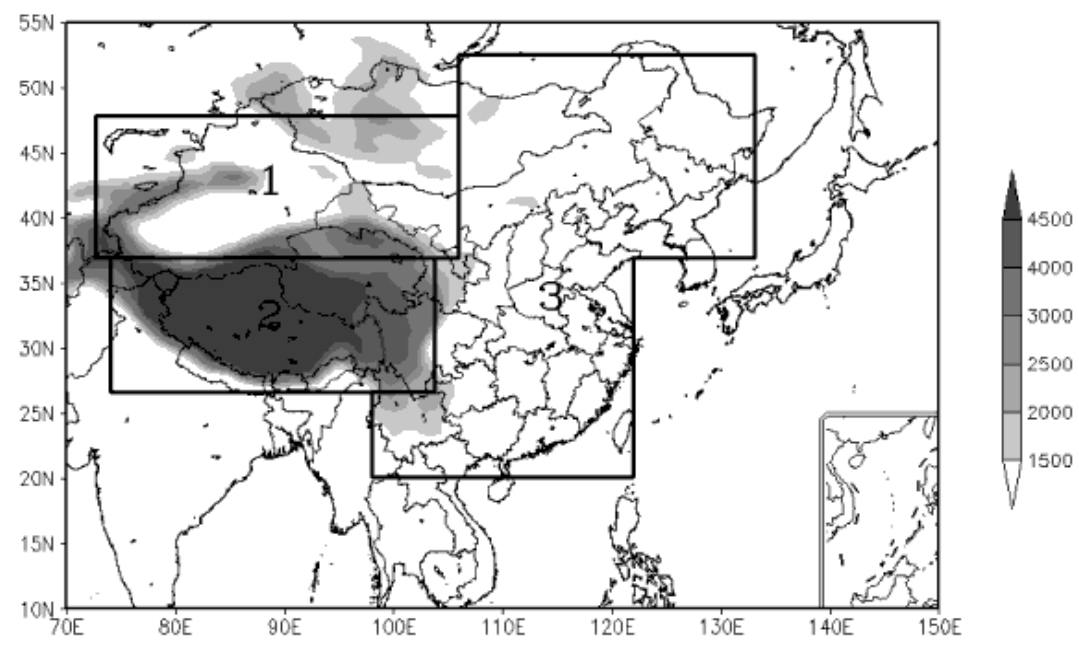

489

490 Figure 1. Topographic map of China. The polygons indicate the three sub-regions

491 defined as non-monsoon sub-region (1), Tibetan Plateau sub-region (2) and monsoon 492 sub-region (3).

493

494

495

496

497

498 

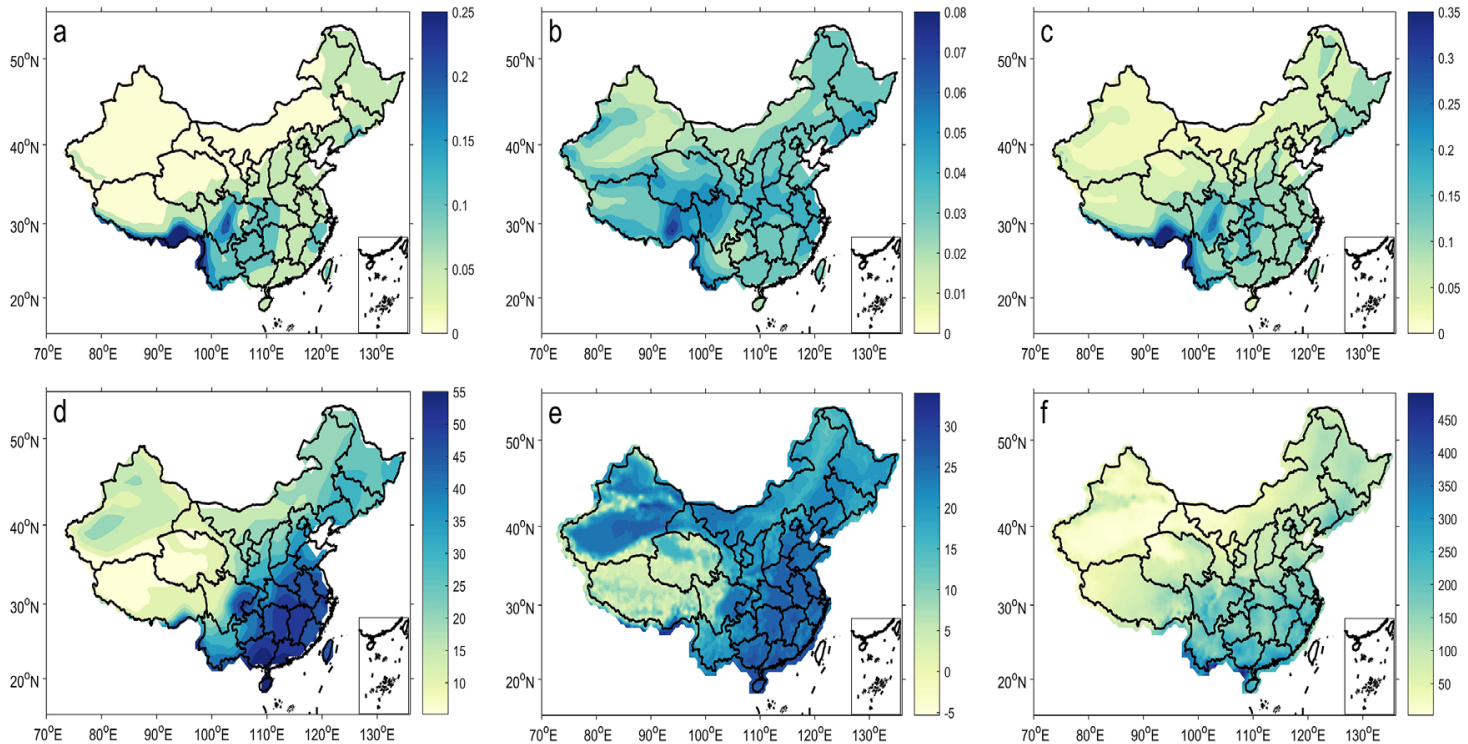

Figure 2. Climatological distribution of vertical integral of a) cloud liquid water content

(VCLWC) $\left(\mathrm{kg} / \mathrm{m}^{2}\right)$, b) cloud ice water content (VCIWC) $\left.\left(\mathrm{kg} / \mathrm{m}^{2}\right), \mathrm{c}\right)$ cloud water content (VCWC) $\left(\mathrm{kg} / \mathrm{m}^{2}\right)$, d) precipitable water $(\mathrm{PW})(\mathrm{mm})$, e) surface mean 
510 Figure 3. Pressure-latitude cross sections of mean cloud liquid water content (CLWC), 511 cloud ice water content (CIWC) and cloud water content (CWC) across the monsoon 512 sub-region between $106-122^{\circ} \mathrm{E}$ (panels a,b,c), the non-monsoon sub-region between $513 \quad 73-106^{\circ} \mathrm{E}$ (panels d,e,f), and the Tibetan Plateau sub-region between $74-104^{\circ} \mathrm{E}$ (panels $514 \mathrm{~g}, \mathrm{~h}, \mathrm{i})$. All units are $\mathrm{g} / \mathrm{kg}$, and black dotted lines are isotherms with an interval of $5^{\circ} \mathrm{C}$. 515 516 517 518 519 520 
522 Figure 4. Time series of vertical integral of a) cloud liquid water content $\left.\left(\mathrm{kg} / \mathrm{m}^{2}\right), \mathrm{b}\right)$

523 cloud ice water content $\left(\mathrm{kg} / \mathrm{m}^{2}\right)$, c) cloud water content $\left.\left(\mathrm{kg} / \mathrm{m}^{2}\right), \mathrm{d}\right)$ precipitable water $524(\mathrm{~mm})$, e) surface mean temperature $\left({ }^{\circ} \mathrm{C}\right)$ and $\left.\mathrm{f}\right)$ precipitation $(\mathrm{mm})$ in the monsoon subregion (top panel), non-monsoon sub-region (middle panel) and Tibetan Plateau sub-

526 region (bottom panel) in China in summer during 1979-2016. The black curve is a 9

527 year moving average, and the blue dotted line is the linear trend. 

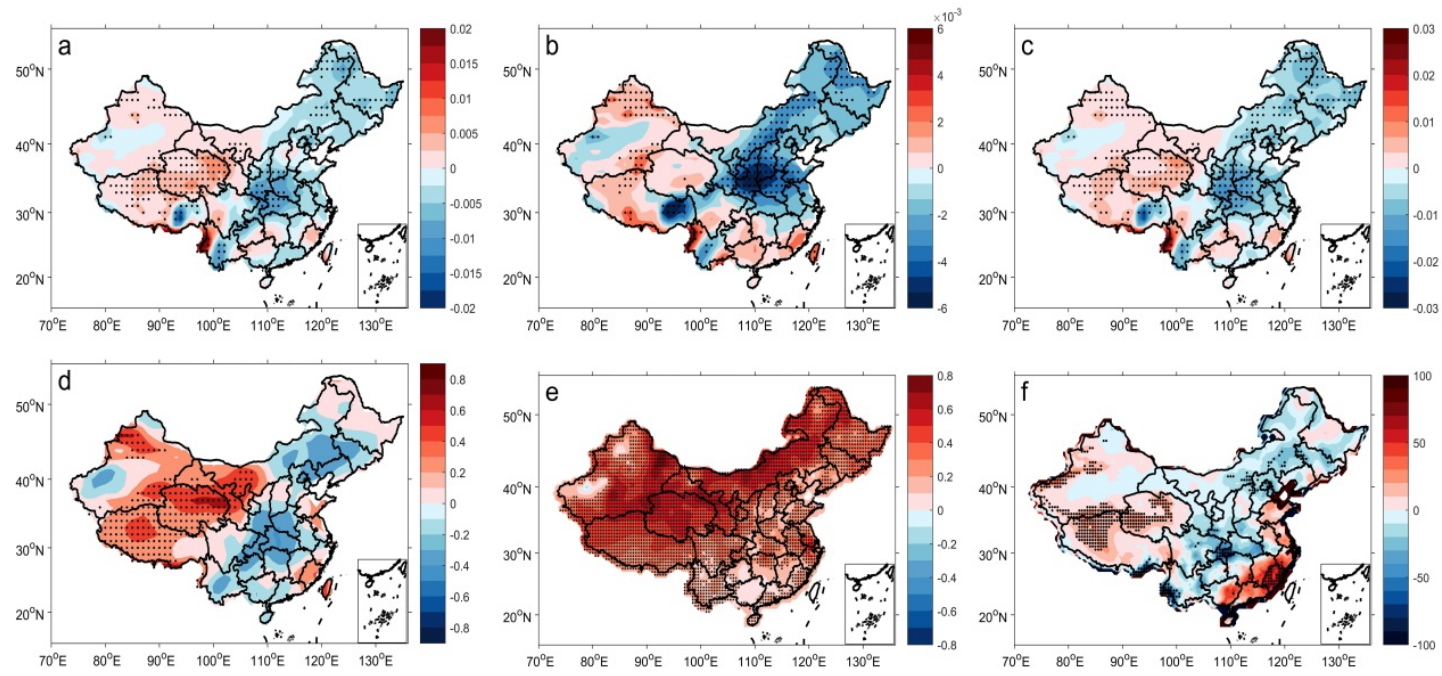

Figure 5. Spatial trends of vertical integral of a) cloud liquid water content

$530\left(\mathrm{~kg} / \mathrm{m}^{2} /\right.$ decade $)$, b) cloud ice water content $\left(\mathrm{kg} / \mathrm{m}^{2} /\right.$ decade $)$, c) cloud water content

$531\left(\mathrm{~kg} / \mathrm{m}^{2} /\right.$ decade $\left.), \mathrm{d}\right)$ precipitable water ( $\mathrm{mm} /$ decade), e) surface mean temperature $\left({ }^{\circ} \mathrm{C}\right.$

532 /decade), and f) precipitation (mm/decade) in China in summer during 1979-2016. The

533 stippled area indicates significance at the level of 0.05. 

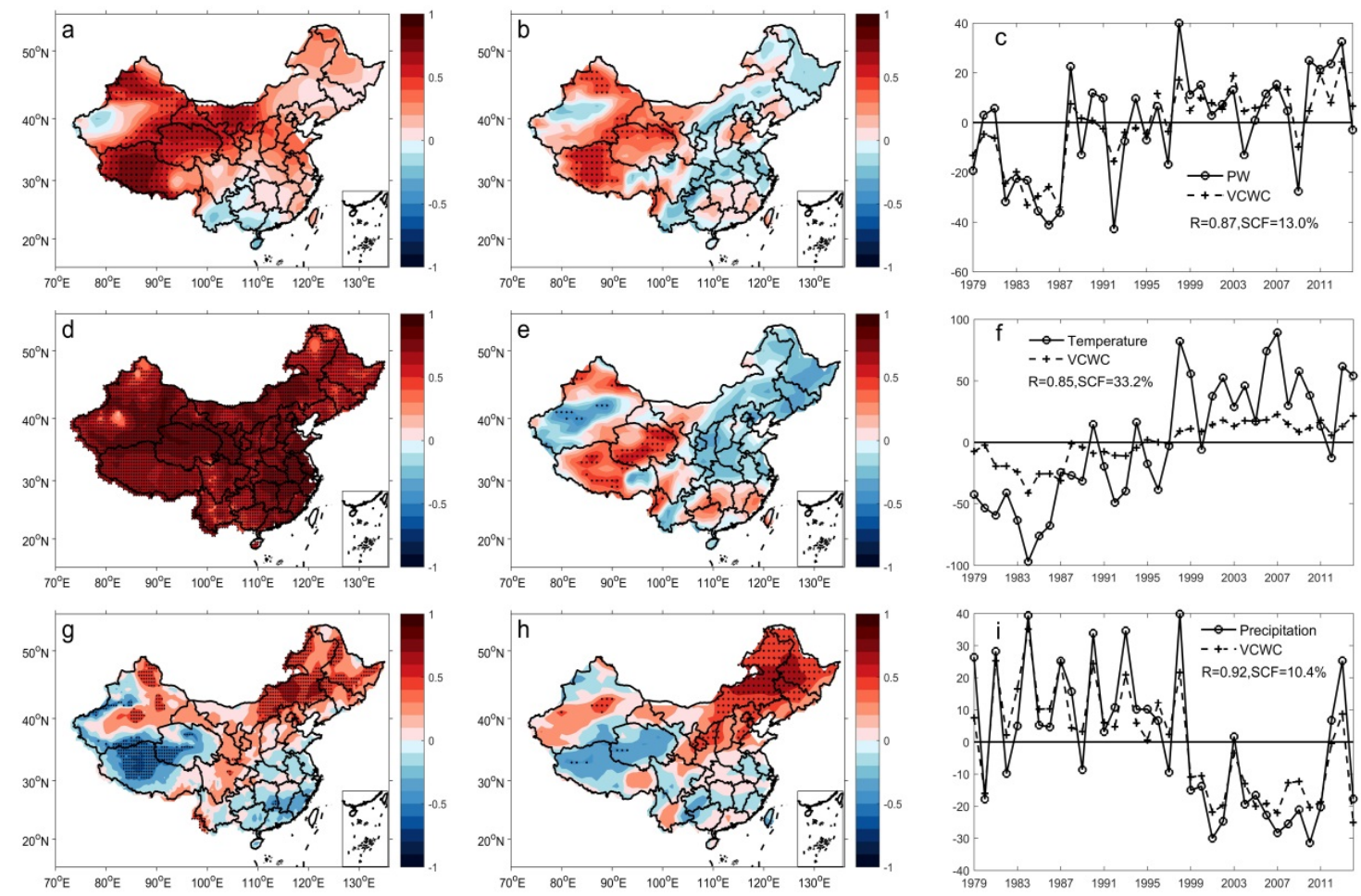

546 Figure 6. Heterogeneous correlation and time coefficient of the first mode of SVD:

547 panels a-c: precipitable water (PW) and vertical integral of cloud water content

548 (VCWC); panels d-f: surface mean temperature and VCWC; panels g-i: precipitation and VCWC. Stippled areas indicate significance at the level of 0.1. R and SCF indicate the correlation coefficient and squared covariance fraction, respectively. 

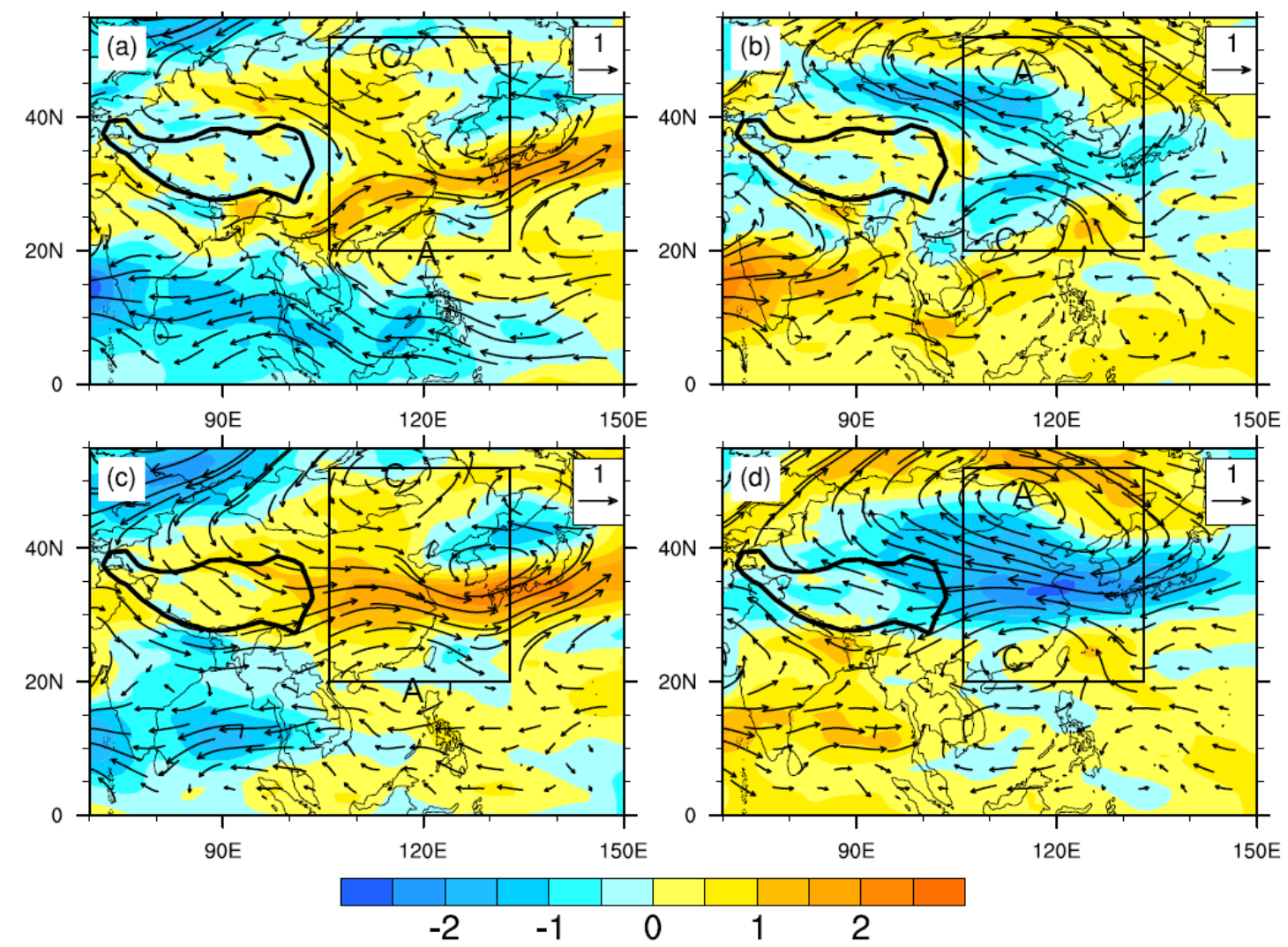

Figure 7. Differences in wind field and wind speed at $700 \mathrm{hPa}$ (top panel a and b) and

$500 \mathrm{hPa}$ (bottom panel $\mathrm{c}$ and $\mathrm{d}$ ) between composites of strongly positive and negative mean vertical integral of cloud water content (VCWC, left panel a and c)/surface mean temperature (right panel $\mathrm{b}$ and $\mathrm{d}$ ). Extreme years are defined by deviations exceeding $\pm 0.8 \sigma$ for the monsoon sub-region (box) during 1979-2016. Strongly positive VCWC years include 1979, 1983, 1993, 1995, 1998, 1999, 2003, and strongly negative VCWC years include 2001, 2006, 2007, 2008, 2009, 2010, 2011, and 2013, respectively. Strongly positive surface mean temperatures occurred in 1994, 1997, 2000, 2001, 2005, 2006, 2007, 2010, 2011, 2013, and strongly negative surface mean temperature occurred in 1979, 1983, 1984, 1986, 1987, 1989, 1992, 1993, 1996, respectively. The anomalous flow is represented by the arrows, and the shaded areas indicate wind speed difference. Positive/negative differences mean enhanced westerly/easterly flow. "A" and "C" represent anticyclonic and cyclonic systems. 

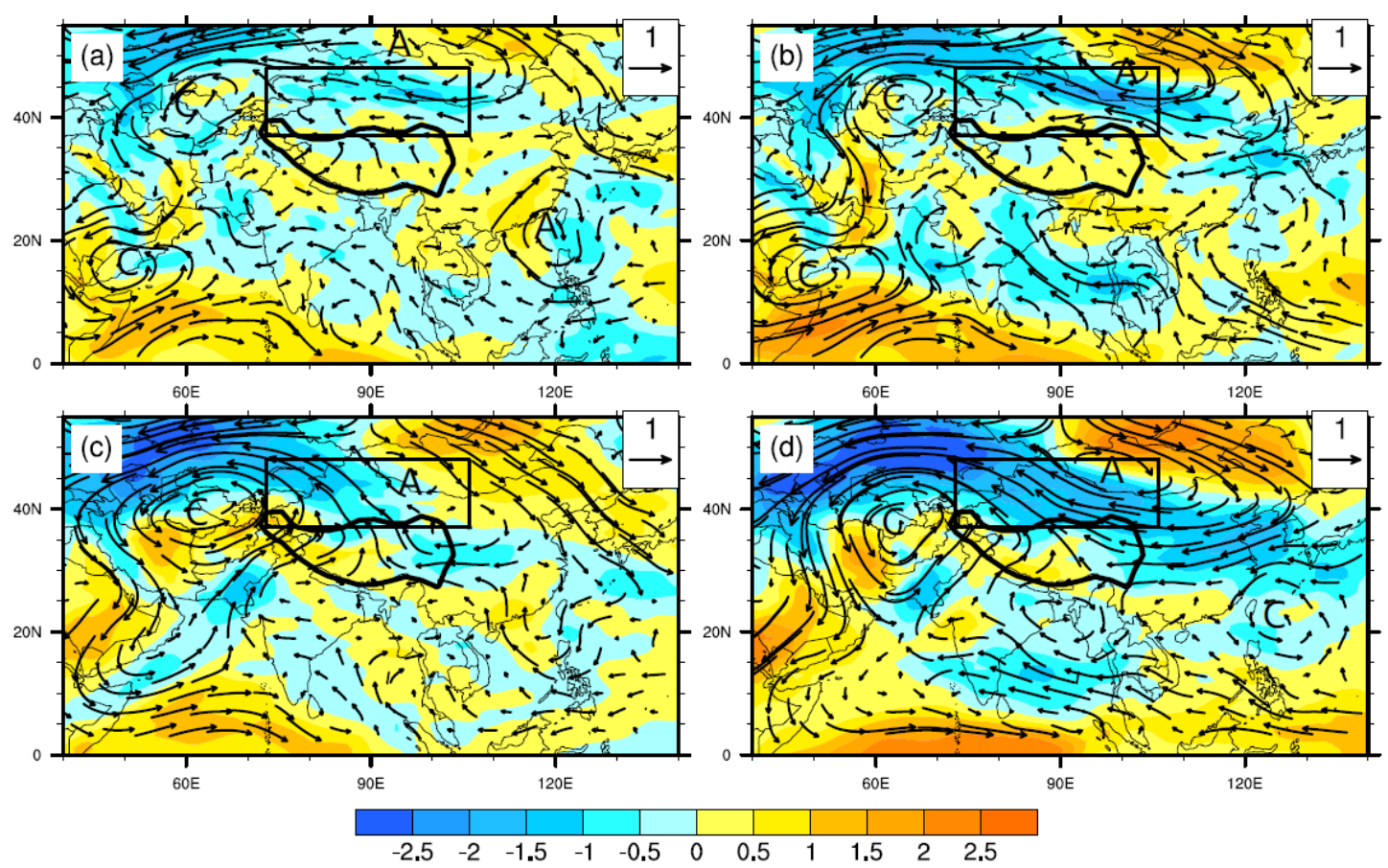

574

575

Figure 8. Differences in wind field and wind speed at $700 \mathrm{hPa}$ (top panel a and b) and $500 \mathrm{hPa}$ (bottom panel $\mathrm{c}$ and d) between composites of strongly positive and negative mean vertical integral of cloud water content (VCWC, left panel a and c)/precipitable water (right panel $b$ and $d$ ). Extreme years are defined by deviations exceeding $\pm 0.8 \sigma$ for the non-monsoon sub-region (box) during 1979-2016. Strongly positive VCWC was recorded in 1981, 1987, 1993, 1996, 2013, 2016, and strongly negative VCWC in 1980, 1983, 1984, 1985, 1990, 1995, 2008,2009, respectively. Strongly positive precipitable water was recorded in 1981, 1998, 1999, 2000, 2012, 2016, and strongly negative precipitable water in 1980, 1982, 1984, 1985, 2008, 2009, respectively. . The anomalous flow is represented by the arrows, and the shaded areas indicate wind speed difference. Positive/negative differences mean enhanced westerly/easterly flow. "A" and "C" represent anticyclonic and cyclonic systems. The key is the same as in Figure 7. 

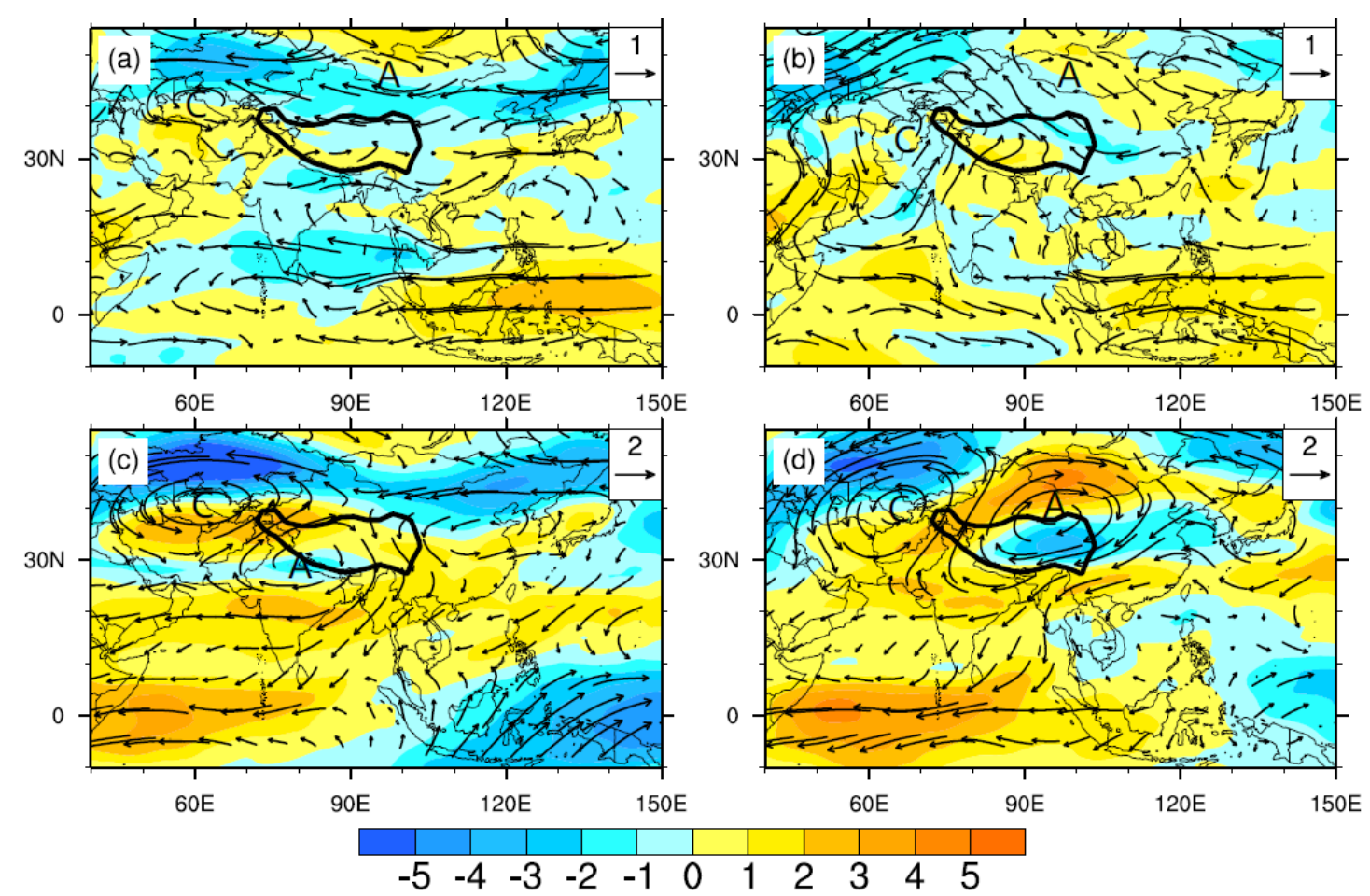

Figure 9. Differences in wind field and wind speed at $500 \mathrm{hPa}$ (top panel a and b) and $200 \mathrm{hPa}$ (bottom panel c and d) between composites of strongly positive and negative mean vertical integral of cloud water content (VCWC, left panel a and c)/surface mean temperature (right panel $\mathrm{b}$ and $\mathrm{d}$ ). Extreme years are defined by deviations exceeding $\pm 0.8 \sigma$ for the Tibetan plateau sub-region during 1979-2016. Strongly positive VCWC occurred in 1988, 1998, 1999, 2003, 2008, and strongly negative VCWC occurred in 1979,1982, 1983, 1984, 1986, 1992, 1994, 2006, 2009, 2013, respectively. Strongly positive surface mean temperature was recorded in 1998, 2006, 2009, 2010, 2012, 2013, 2014, and strongly negative surface mean temperature in 1979, 1980, 1982, 1983, 1984 , 1985, 1986, 1989, 1992, respectively. . The anomalous flow is represented by the arrows, and the shaded areas indicate wind speed difference. Positive/negative 600 differences mean enhanced westerly/easterly flow. " $\mathrm{A}$ " and "C" represent anticyclonic and cyclonic systems. The key is the same as in Figure 7. 

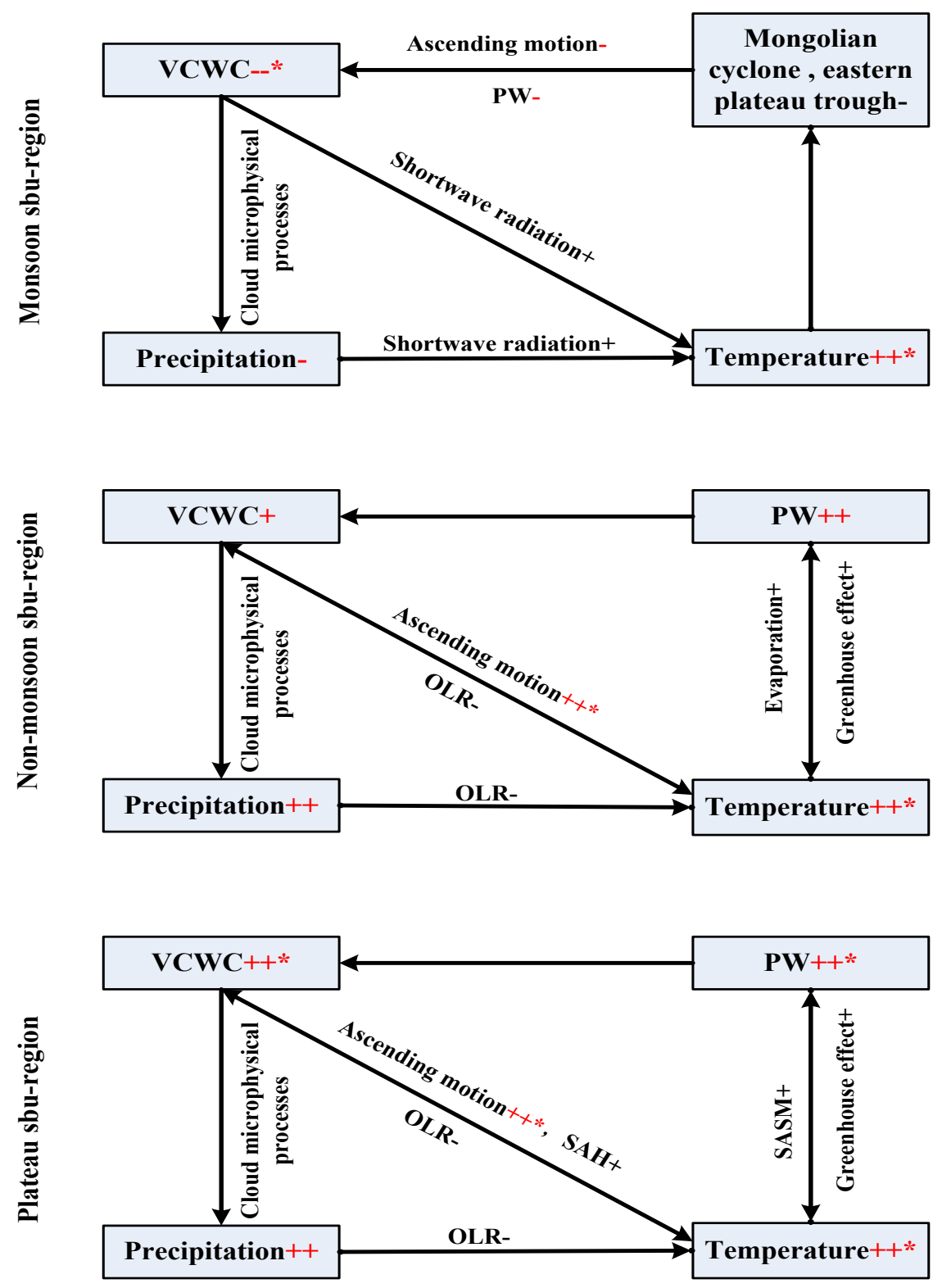

Figure 10. A schematic representation of the climate system which influences summer 608 cloud water content in the three sub-regions of China. SAH, SASM and OLR indicate 609 south Asian high, south Asian monsoon, and outgoing longwave radiation, respectively. 610 The red +/-, ++/--, ++*/--* represent weak increase/decrease, strong increase/decrease, 611 strong increase/decrease which passes significance at the level of 0.05 . 
617 Table 1. Trends of vertical integral of cloud water content (VCWC, g/ $\mathrm{m}^{2} / \mathrm{decade}$ ), 618 precipitation ( $\mathrm{mm} /$ decade), precipitable water $(\mathrm{PW}, \mathrm{mm} /$ decade) and surface mean 619 temperature $\left({ }^{\circ} \mathrm{C} /\right.$ decade) in the non-monsoon sub-region, monsoon sub-region and 620 Tibetan Plateau sub-region during 1979-2016. Values with * and ** indicate 621 significance at the level of 0.05 and 0.01 , respectively.

\begin{tabular}{ccccc}
\hline & VCWC & Precipitation & PW & $\begin{array}{c}\text { Surface mean } \\
\text { temperature }\end{array}$ \\
\hline $\begin{array}{c}\text { Monsoon sub- } \\
\text { region }\end{array}$ & $-2.71^{*}$ & -0.97 & 0 & $0.28^{* *}$ \\
$\begin{array}{c}\text { Non-monsoon } \\
\text { sub-region }\end{array}$ & 1.04 & 3.17 & 0.19 & $0.43^{* *}$ \\
$\begin{array}{c}\text { Tibetan Plateau } \\
\text { sub-region }\end{array}$ & $3.39^{*}$ & 3.59 & $0.42^{* *}$ & $0.41^{* *}$ \\
\hline
\end{tabular}

622

623

624

625

626

627

628

629

630

631

632

633

634

635

636

637

638

639

640

641

642

643

644

645 
646 Table 2. Correlations between vertical integral of cloud water content (VCWC), cloud

647 liquid water content (VCLWC), cloud ice water content (VCIWC), precipitation,

648 precipitable water (PW) and surface mean temperature in the non-monsoon sub-region,

649 monsoon sub-region and Tibetan Plateau sub-region during 1979-2016. Value with *

650 and $* *$ indicate significance at the level of 0.05 and 0.01 , respectively.

\begin{tabular}{lccccccccc}
\hline & \multicolumn{3}{c}{ Monsoon sub-region } & \multicolumn{3}{c}{ Non-monsoon sub-region } & \multicolumn{2}{c}{ Tibetan Plateau sub-region } \\
\hline & VCWC & VCLWC & VCIWC & VCWC & VCLWC & VCIWC & VCWC & VCLWC & VCIWC \\
Precipitation & $0.51^{* *}$ & $0.48^{* *}$ & $0.51^{* *}$ & $0.73^{* *}$ & $0.67^{* *}$ & $0.65^{* *}$ & $0.44^{* *}$ & $0.44^{* *}$ & $0.36^{*}$ \\
Surface mean & - & $-0.55^{* *}$ & $-0.40^{*}$ & -0.05 & -0.08 & 0 & 0.31 & $0.40^{*}$ & 0.02 \\
temperature & $0.51^{* *}$ & & & & & & & & \\
PW & 0.18 & 0.18 & 0.15 & $0.78^{* *}$ & $0.86^{* *}$ & $0.50^{* *}$ & $0.68^{* *}$ & $0.73^{* *}$ & $0.41^{* *}$ \\
\hline
\end{tabular}

